\title{
Utilization of ISTR, ISSR and SRAP molecular markers to reveal and classify Egyptian pomegranates (Punica granatum L.)
}

\author{
Mohamed Hamdy Amar*, Mohamed Abd. S. El-Zayat
}

\section{Egyptian Deserts Gene Bank, Desert Research Center, Egypt}

*Corresponding author: mohamed.amar@wbgcas.cn

These authors contributed equally to this work.

\begin{abstract}
This study offers the comprehensive analysis of the genetic diversity among six local varieties (Manfalouti; Nab El-Gamal; Hegazy; Wardi; Assuity; Araby) and three international varieties (Wonderful; Marked Bani Rafie; Red Bani Rafie) of pomegranate in Egypt, based on the behavior of ISTR, ISSR and SRAP markers profiles. A set of 24 ISTR, 16 ISSR and 30 SRAP primers combination were compared, concerning exposed the degree of resolution and efficiency of the discriminating capacity technique alongside with the level of genetic polymorphism, to determine which varieties evolved from the others. Considering the results, SRAP assay had superior, more sensitive, higher discrimination capacity and gives much more evidence about the total number of effective alleles (1411), number of polymorphic amplicons (312), PIC (0.94), assay efficiency index (47.04), effective multiples ratio (10.04) and marker index (9.74). Unexpectedly, the ISTR profile demonstrated a significant moderate level of polymorphism among tested genotypes. To further determine the genetic relationships and the distance among varieties, a graphic demonstration of combined UPGMA tree and the PCA analysis did assemble with clear resolution and accurate along with three categories.Our findings confirm that combining different marker system were greatly better and more effective considered an important priority step toward diversity study and characterization. We can point out that, the two-widespread varieties in Egypt Manfalouti, and Nab El-Gamal, formed a high homogeneity in genetic similarity with the Wonderful, as an essential global species for breeding programs, efforts widening the genetic base of pomegranates and the introduction of new genotypes in Egypt
\end{abstract}

Keywords: Discriminating capacity, Genetic diversity, Pomegranate (Punica granatum L.), PCA, UPGMA tree; UPGMA_ Unweighted Pair Group Method with Arithmetic Mean.

Abbreviations: ISSR_Inter Simple Sequence Repeat; ISTR_Inverse Sequence Tagged Repeat; PCA_Principal Coordinates Analysis SRAP_Sequence Related Amplified Polymorphism.

\section{Introduction}

Pomegranate belongs to the family Lythraceae (formerly, Punicaceae), and the most commonly cultivated species, Punica granatum L. (Alsadi et al., 2015). It is one of the oldest known edible fruit tree species, with a large-scale series geographical global distribution (Silva et al., 2013). Punica granatum L. considered that it originated in Central Asia, it is native to the area occupying from Iran to the Himalayas in northern India (Chandra et al., 2010; Chauhan et al., 2012; Silva et al., 2013). Worldwide there are three mega and five macro-centers of origin and genetic diversity of pomegranate (Levin 2006a, b; Chandra et al., 2010). Mediterranean countries are the main center for commercial cultivation, it has been cultivated and naturalized over the whole Mediterranean region since ancient times including Egypt and North Africa (Silva et al., 2013). Globally, the genetic diversity of pomegranate is demonstrated by an excess of 500 globallydistributed varieties, approximately fifty of which are identified to be commercially cultivated (IPGRI, 2001). Apparently, classification of pomegranate genotypes based on morphological characteristics such as fruit size, color and acidity were associated with the environmental changes, making classifications based on morphological traits unreliable (Hajiahmadi et al., 2013). Hence, with the aid of molecular identification of pomegranate, it is becoming easier and faster to characterize germplasm and identify genotypes with desirable traits in breeding programs. Consequently, it is vital to conserve the gene pool alongside with the behavior of genes in pomegranate germplasm, to maintain a broad genetic base for the future aspect of breeding strategy in pomegranate (Rana et al., 2007). Numerous molecular marker investigations have been verified in $P$. granatum, such as RAPD (Talebi et al., 2003); ISSR (Talebi et al., 2005; Narzary et al., 2009); F-AFLP (Yuan et al., 2007); RFLP (Melgarejo et al., 2009); AFLP (Moslemi et al., 2010); SRAP (Soleimani et al., 2012); SSR (Rania et al., 2012; Hasnaoui et al., 2012); REMAP (Zhao et al., 2013) and chloroplast DNA (Hajiahmadi et al., 2013). In fact, the choice of most appropriate technology for a specific study is not obvious and depends primarily on purpose of the research as well as the degree of polymorphism and genetic assembly of the species. ISTR is a retrotransposon-based marker (Rhode 1996) which has been seen in every type of organism, are ubiquitous, dynamic and abundant in eukaryotic genomes (Torresmorán et al., 2012; Amar and Abd El Salam 2013). Hence, ISTR markers would be expected to be co-dominant and involve a various level of genetic variability, i.e. transposition results, then arbitrary markers systems such as RAPD or AFLPs, which sense polymorphism from simple nucleotide changes to genomic rearrangements (Kalendar, 2011). ISSR profile is a PCR-based method which uses microsatellites as primers in a single 
reaction targeting comprise a few highly informative multiallelic loci. (Kumar et al., 2013). As for SRAP, sequencerelated amplified polymorphism is a novel molecular marker system which is based on open reading frames (ORFs) developed from genome sequence data of Arabidopsis. As PCR-based markers, SRAP have many advantages, including the requirement for a relatively small amount of template genomic DNA, and good levels of polymorphism in many plant species (Aneja et al., 2012; Robarts and Wolfe 2014). The three molecular markers listed above have the facility to detect different parts of the genome, they have a dominant or co-dominant inheritance and the usage together may be more effectiveness (Velascoramirez et al., 2014). In this sense, comparisons are required to decide which system is most appropriate for the issue being examined (Scariot et al., 2007). In the current investigation, we sought to determine a new basis for the ongoing discussion about; first, conducted comparison on the performance and the discrimination capacity of three molecular markers including ISTR, ISSR and SRAP; secondly, to assess the taxonomic uncertainties and varieties limits concerning the genetic diversity of Egyptian $P$. granatum germplasm. To our knowledge, till now there has been no report about the comparison of discriminating capacity and efficiency of ISSR, SRAP and ISTR marker system in Egyptian $P$. granatum germplasm.

\section{Results}

Comparison of polymorphic levels and informativeness obtained with ISTR, ISSR and SRAP markers

The levels of polymorphism detected with each marker system (ISTR, ISSR, and SRAP) and the index comparing their informativeness are represented in (Table 1) and (Fig 3). The three marker systems examined turned out to be valuable tools for detection of polymorphism and assessing genetic diversity in pomegranate germplasm, but the degree of resolution depended on the technique applied.

We initially tested 70 combinations of ISTR primers, 20 of ISSR primers and 64 combinations of SRAP primers between the nine Egyptian cultivars of pomegranate. Amongst all, 24 ISTR, 16 ISSR and 30 SRAP primers presented various levels of polymorphism as exposed in (Figures 1a-c and 2) and (Table1). The total number of allele scored was 365 for SRAP with relatively high, and with an intermediate value of 219 for ISTR, while ISSR showed the lowest value (175). On behalf to, the total numbers of polymorphic amplicons ( $n p)$ was varied from 118 for ISSR, 143 for ISTR to 312 for SRAP markers. However, the total number of effective alleles $(\mathrm{Ne})$ was correlate positively with the average number of polymorphic amplicons per assay unit $(n p / U)$ and the number of allele /assay unit $(n u)$. With the view of the effective number of patterns assay unit ( $\mathrm{p}$-value) were obtained from the marker SRAP (14.17), ISSR (7.5) and ISTR (6.33), respectively. The effective number of patterns referee to the size of an ideal population in which, given the frequencies of the patterns obtained with a marker system, all the individuals can be notable. With the view of the average of PIC for ISTR, ISSR and SRAP markers system were nearly similar and relatively high, $0.93,0.93$ and 0.94 , respectively. Herein, the above result exposed that SRAP markers were the most suitable marker in all observed parameter and PIC values.
Comparison of the discriminating capacity of ISTR, ISSR and SRAP markers

A comparative scenario of the discriminating capacity of ISTR, ISSR and SRAP markers are summarized in (Table 2) and (Fig. 3). The Effective number of alleles per locus (ne) for ISTR, ISSR and SRAP were a nearly similar value (14.7, 15.15 and 16.12) respectively. This was reflected by the higher values of the expected heterozygosity (Hep) of the polymorphic loci with a percentage of 0.93 for ISTR, ISSR and SRAP markers. The three parameters, assay efficiency index, effective multiples ratio and marker index were observed more highly from SRAP marker highlights the distinctive nature of these markers compared to ISSR and ISTR $(1.3 \times, 2.4 \times$, respectively). Herein the highest assay efficiency index and marker index value for SRAP marker as result of greater effective multiples ratio component, suggesting that SRAP has a higher discriminating capacity for quantifying the genetic diversity and can simultaneously detect numerous polymorphic markers per reaction.

\section{Genetic diversity and phylogenetic relationship}

The data from all ISTR, ISSR and SRAP amplification amplicons were used in the similarity evaluation. The genetic similarity matrix among all materials used in the present work was obtained (Table 3, a, b, c). Based on 759 alleles a similarity matrix was calculated according to Dice's coefficient. The similarity values among the studied genotypes ranged from 0.31 to 0.83 . The highest similarity was between the three pairs, Hegazy \& Marked Bani Rafie (0.83), Wonderful \& Red Bani Rafie (0.80) and Wardi \& Marked Bani Rafie (0.76) for SRAP, ISSR, and ISTR, respectively. However, the lowest similarity was recorded between, Assuity \& Red Bani Rafie (0.31), Manfalouti \& Nab El-Gamal (0.37) and Wardi \& Araby (0.56) for ISTR, ISSR, and SRAP, respectively. Based on data obtain from ISTR, ISSR and SRAP tree, a combined UPGMA tree was constructed as illustrated in (Fig 4). Herein, a little modification in the positioning of some genotypes was observed in the sub-clade tree formed, using different markers systems and the phylogenetic tree from SRAP data was most compatible with a combined tree.

The phylogenetic analysis revealed numerous wellsupported clades with great bootstrap values. In total, we observed three strongly supported clades, which were clearly distinguishable among the local and the international varieties of pomegranate in Egypt. The first clade was clustered jointly Wonderful, Manfalouti and Nab El-Gamal. In context, the second clade represents Hegazy is closely related to Wardi, at the same time being sister to Araby. Meanwhile, the two varieties Assuity and Red Bani Rafie were closed together as a sister to Marked Bani Rafie.

To further determine the genetic relationships among the nine Egyptian varieties of pomegranate, a graphic demonstration of the principal coordinate analysis (PCA) was presented (Fig 5). The results indicated that it could be divided into three major categories. Category I compressed the two international varieties Marked Bani Rafie, Red Bani Rafie and Assuity as one of the local varieties. Category II assembled Araby, Wardi and Hegazy. Meanwhile, the local varieties Manfalouti and Nab El-Gamal are grouped jointly with the international variety Wonderful in the category III. These results showed that most of the international varieties were isolated independently with nesting to the local variety 
Assuity. In contrast, the local variety was formed in two categories with a high homogeneity in genotypes correlation with nested to Wonderful, as one of the essential international varieties.

\section{Discussion}

The systematic behavior and phylogenetic affinities of the Egyptian pomegranate varieties are still obscured, and unsolved problems concerning their biology and taxonomy need further verification and confirmation. Thus, investigation of levels of genetic diversity is an important precursor for the study of plant species and will provide insights into the evolution of the species. In fact, the taxonomic ambiguities persisting with the systematic position of the genus Punica also needs to be resolved and the molecular methods will be the best possible approach for this (Ranade et al., 2009). This study offers the comprehensive analysis of the genetic diversity among six local varieties (Manfalouti; Nab El-Gamal; Hegazy; Wardi; Assuity; Araby) and three international varieties (Wonderful; Marked Bani Rafie; Red Bani Rafie) of pomegranate under North Sinai conditions, Egypt, based on the behavior of the three molecular markers profiles ISTR, ISSR and SRAP. In detail, the purpose of the present study was to explore the efficiency of the discriminating capacity technique alongside with the level of genetic polymorphism to determine which varieties evolved from the others. In the framework, Ferrao et al., (2012) indicated that the efficiency of a molecular marker is balanced among the level of polymorphism it can distinguish and its capacity to identify numerous polymorphisms; deciding which technique is the most suitable based on several aspects, counting the objective of the research, genetic structure and the resources presented. Interestingly, our results of the molecular diversity data can obtain desirable differentiation among the tested pomegranate varieties. Regarding the level of polymorphism, the highest value was obtained from the SRAP analysis. This is due to the superior value of the total number of effective alleles, the effective number of patterns/ assay unit and the average number of polymorphic amplicons /assay unit. This finding agrees with previous studies where SRAPs proved to be high effective tools were compared to other marker systems that used each technique separately in pomegranate germplasm, such as, RAPD (Sarkhosh et al., 2006; Narzary et al., 2009), ISSR (Talebi et al., 2005; Narzary et al., 2010), SSR (KoohiDehkordi et al., 2007; Pirseyedi et al., 2010) and SRAP (Soleimani et al., 2012). Other studies in several plants have also confirmed that SRAP is superior information than other methods, for example, RAPD (Liu et al., 2007), ISSR (LiWang et al., 2008) and SSR (Amar et al., 2011). Recently, Robarts and Wolfe (2014) propose that SRAP markers should be employed for research addressing hypotheses in plant systematics and these markers have verified to be robust and highly variable, on par with AFLP. On behalf of the behavior of ISSR profile, the level of polymorphism is relatively high; this is probably due to the value of the effective number of patterns per assay units. This is very substantial for the management of germplasm banks where several cultivars are complex need to be accurately and classification (Belaj et al., 2003). Parallel results were reported in pomegranate by Sarkhosh et al., (2006) evaluate Iranian genotypes, while that Ghobadi et al., (2005) pointed to a high level of genetic similarity $(65 \%)$ between the 24 Iranian pomegranate genotypes across six ISSR markers. In subsequent studies, (Talebi t al., 2011) described that ISSR markers exhibited higher levels of polymorphisms for revealing molecular diversity among pomegranate cultivars. Additionally, Pitsiouni et al., (2012), confirmed that the uses of ISSR among the 40 Greek accessions of pomegranate genotypes gave an adequate number of polymorphic level among wild and cultivated Pomegranate. In the case of ISTR, unexpectedly, this profile demonstrated a moderate level of polymorphism among tested genotypes. This level of polymorphism, associated with ISTR markers, is to be certainly because of the correlation with the total number of effective alleles and the number of allele assay unit, responsible for generating ISTR allelic diversity, which is in concurrence with earlier reports in many plant species (Du et al., 2009; Biswas et al., 2011; Velascoramirez et al., 2014). This finding also agrees with the results of Aga and Bryngelsson (2005), confirmed that ISTR revealed the mild level of genetic variation within a gene pool of $C$. arabica in Ethiopia. By this criterion, the activity of ISTR as a retrotransposon are affected by the transcriptionally inactive, or silent in somatic tissues but active through particular stages of plant development and under the effect of stressful conditions (Torresmorán et al., 2012). Among the discrimination capacity of marker systems evaluated SRAP> ISSR > IRAP were found to be more effectiveness in the estimate of molecular diversity among the Egyptian pomegranate varieties; SRAP was evident superior through the large values of the average number of polymorphic amplicons assay unit, PIC, assay efficiency index, effective multiples ratio and marker index. Mainly, the marker index (MI) is a convenient estimate for marker efficiency (Milbourne et al., 1997; Li and Quiros 2001; Li et al., 2010; Amar and Abd El Wahab, 2013). By this criterion, arithmetically 1.3 fold and 2.4 fold higher MI calculated for SRAP in comparison to ISSR and ISTR, highlights the distinctive nature of the SRAP assay. Rather, the result of the SRAP profile was ORF-based marker system targeting functional regions of the pomegranate genome, and resulting adequate polymorphism, furnished sufficient information for influential the genetic diversity and population genetic structure of the pomegranate varieties (Soleimani et al., 2012). Recently, Li et al., (2013) recommended that SRAP has advantages with a wide range of applications in plant breeding over other molecular detection techniques in gene tagging and cloning and allows screening thousands of loci shortly to pinpoint the genetic position underlying the trait of interest. Our results approved with several research article confirmed that an SRAP marker had the greatest discrimination capacity of polymorphism, and results in a moderate number of co-dominant markers with efficient in marker assisted selection in plant breeding and genetic diversity of many plant species (Agarwal et al., 2008; Dong et al., 2010; Li et al., 2010; Aneja et al., 2012; Robarts and Wolfe 2014).

In Table (4), the results for the correlation coefficients $(r)$ among similarity matrices are presented. Values of $(r)$ were non-significant correlations were observed when comparing the ISSR and ISTR (-0.111) markers and between SRAP and ISTR (-0.031). While the significant correlations to be found among the ISSR and SRAP with a value of 0.43 . The low correlations among different molecular marker systems show the importance of using different markers for estimating diversity and genetic similarity. Because this issue, Velascoramirez et al., (2014) recommended that the information that is generated by various markers had a valuable capacity for genetic studies involving both, diversity and relationships. By this criterion, the combining different marker system was critically better for diversity study as recommended through numerous reports such as (Jhang et al., 
Table 1. Levels of polymorphism and PIC value generated by ISTR, ISSR and SRAP and assays among nine Egyptian varieties of pomegranate.

\begin{tabular}{|c|c|c|c|c|c|c|c|c|c|c|}
\hline $\begin{array}{l}\text { Index with their } \\
\text { abbreviations }\end{array}$ & $\begin{array}{c}\text { Number of } \\
\text { markers }\end{array}$ & $\begin{array}{c}\text { Number of } \\
\text { allele }\end{array}$ & $\begin{array}{l}\text { Number of allele } \\
\text { /assay unit }\end{array}$ & $\begin{array}{c}\text { Total } \\
\text { Banding } \\
\text { pattern }\end{array}$ & $\begin{array}{l}\text { Effective number of } \\
\text { patterns/ assay unit }\end{array}$ & $\begin{array}{l}\text { Total number of } \\
\text { effective alleles }\end{array}$ & $\begin{array}{l}\text { Number of } \\
\text { monomorphic } \\
\text { amplicons }\end{array}$ & $\begin{array}{l}\text { Number of } \\
\text { polymorphic } \\
\text { amplicons }\end{array}$ & $\begin{array}{c}\text { Average number of } \\
\text { polymorphic amplicons } \\
\text { /assay unit }\end{array}$ & $\begin{array}{c}\text { PIC } \\
\text { Value }\end{array}$ \\
\hline Markers Name & $U$ & $L$ & $n_{u}$ & $B p$ & $p$ & $\mathrm{Ne}$ & $n_{n p}$ & $n_{p}$ & $\mathrm{n}_{p} / U$ & $\%$ \\
\hline ISTR & 24 & 219 & 9.13 & 152 & 6.33 & 464 & 76 & 143 & 5.96 & 0.93 \\
\hline ISSR & 16 & 175 & 10.94 & 120 & 7.50 & 578 & 57 & 118 & 7.38 & 0.93 \\
\hline SRAP & 30 & 365 & 12.17 & 425 & 14.17 & 1411 & 53 & 312 & 10.40 & 0.94 \\
\hline
\end{tabular}

Table 2. Comparison of information obtained with and discriminating capacity of ISSR, SRAP and ISTR markers among nine Egyptian varieties of pomegranate.

\begin{tabular}{|c|c|c|c|c|c|c|c|}
\hline $\begin{array}{l}\text { Index with their } \\
\text { abbreviations }\end{array}$ & $\begin{array}{l}\text { Average of the allele } \\
\text { frequency } \\
\text { (pi2) }\end{array}$ & $\begin{array}{l}\text { Effective number of } \\
\text { alleles per locus } \\
\text { (ne) }\end{array}$ & $\begin{array}{l}\text { Expected heterozygosity of the } \\
\text { polymorphic loci } \\
(\mathrm{He})\end{array}$ & $\begin{array}{c}\text { Fraction of polymorphic } \\
\text { loci } \\
(\beta)\end{array}$ & $\begin{array}{c}\text { Assay efficiency index } \\
\text { (Ai) }\end{array}$ & $\begin{array}{c}\text { Effective multiples } \\
\text { ratio } \\
(E M R)\end{array}$ & $\begin{array}{l}\text { Marker Index } \\
\qquad(M I)\end{array}$ \\
\hline ISTR & 0.068 & 14.7 & 0.932 & 0.65 & 19.37 & 5.96 & 5.55 \\
\hline ISSR & 0.066 & 15.15 & 0.934 & 0.67 & 36.18 & 7.38 & 6.88 \\
\hline SRAP & 0.062 & 16.12 & 0.938 & 0.85 & 47.04 & 10.04 & 9.74 \\
\hline
\end{tabular}

Table 3. a, b and c. Similarity matrix resulting from ISTR, ISSR and SRAP data for the nine pomegranate varieties.

\begin{tabular}{|c|c|c|c|c|c|c|c|c|}
\hline ISTR & Wonderful & Manfalouti & Nab El-Gamal & Hegazy & Wardi & Araby & Assuity & Red Bani Rafie \\
\hline \multicolumn{9}{|l|}{ Wonderful } \\
\hline Manfalouti & 0.527 & & & & & & & \\
\hline Nab El-Gamal & 0.573 & 0.402 & & & & & & \\
\hline Hegazy & 0.625 & 0.538 & 0.444 & & & & & \\
\hline Wardi & 0.688 & 0.744 & 0.723 & 0.649 & & & & \\
\hline Araby & 0.719 & 0.663 & 0.707 & 0.742 & 0.756 & & & \\
\hline Assuity & 0.634 & 0.544 & 0.612 & 0.573 & 0.728 & 0.61 & & \\
\hline Red Bani Rafie & 0.612 & 0.505 & 0.604 & 0.594 & 0.708 & 0.644 & 0.311 & \\
\hline Marked Bani Rafie & 0.602 & 0.578 & 0.64 & 0.647 & 0.766 & 0.685 & 0.533 & 0.434 \\
\hline ISSR & Wonderful & Manfalouti & Nab El-Gamal & Hegazy & Wardi & Araby & Assuity & Red Bani Rafie \\
\hline \multicolumn{9}{|l|}{ Wonderful } \\
\hline Manfalouti & 0.62 & & & & & & & \\
\hline Nab El-Gamal & 0.652 & 0.375 & & & & & & \\
\hline Hegazy & 0.709 & 0.507 & 0.477 & & & & & \\
\hline Wardi & 0.795 & 0.568 & 0.449 & 0.442 & & & & \\
\hline Araby & 0.709 & 0.468 & 0.462 & 0.38 & 0.388 & & & \\
\hline Assuity & 0.643 & 0.488 & 0.396 & 0.439 & 0.41 & 0.425 & & \\
\hline Red Bani Rafie & 0.802 & 0.663 & 0.598 & 0.63 & 0.678 & 0.621 & 0.633 & \\
\hline Marked Bani Rafie & 0.731 & 0.687 & 0.591 & 0.588 & 0.519 & 0.581 & 0.438 & 0.729 \\
\hline SRAP & Wonderful & Manfalouti & Nab El-Gamal & Hegazy & Wardi & Araby & Assuity & Red Bani Rafie \\
\hline \multicolumn{9}{|l|}{ Wonderful } \\
\hline Manfalouti & 0.745 & & & & & & & \\
\hline Nab El-Gamal & 0.806 & 0.757 & & & & & & \\
\hline Hegazy & 0.792 & 0.743 & 0.749 & & & & & \\
\hline Wardi & 0.771 & 0.729 & 0.714 & 0.655 & & & & \\
\hline Araby & 0.764 & 0.749 & 0.754 & 0.655 & 0.561 & & & \\
\hline Assuity & 0.758 & 0.75 & 0.723 & 0.702 & 0.589 & 0.582 & & \\
\hline Red Bani Rafie & 0.758 & 0.77 & 0.769 & 0.732 & 0.692 & 0.67 & 0.599 & \\
\hline Marked Bani Rafie & 0.752 & 0.787 & 0.807 & 0.83 & 0.78 & 0.727 & 0.715 & 0.682 \\
\hline
\end{tabular}


Table 4. Correlation among similarity matrices derived from ISTR, ISSR and SRAP markers.

\begin{tabular}{llll}
\hline Variables & ISSR & SRAP & ISTR \\
\hline ISSR & $\mathbf{1}$ & 0.0089 & 0.51 \\
SRAP & 0.43 & $\mathbf{1}$ & 0.878 \\
ISTR & -0.111 & -0.031 & $\mathbf{1}$ \\
\hline Values in bold are different from 0 with a significance level alpha $=0.05$ & &
\end{tabular}

Values in bold are different from 0 with a significance level alpha $=0.05$

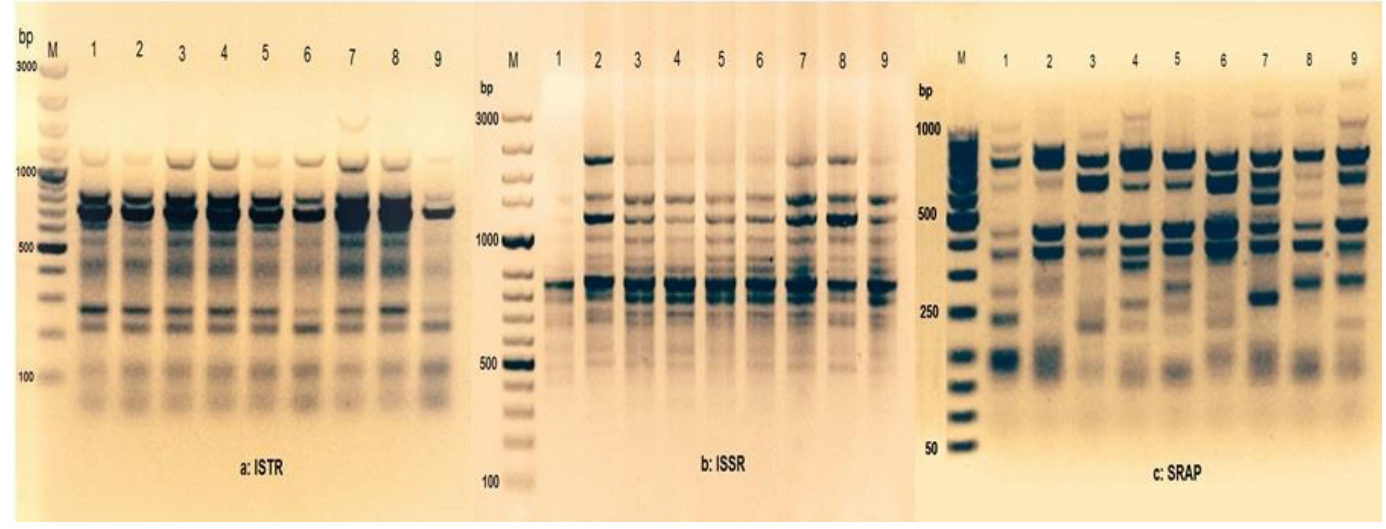

Fig 1. ISTR (A), ISSR(B) and SRAP (C) profiles of nine Egyptian pomegranate varieties.

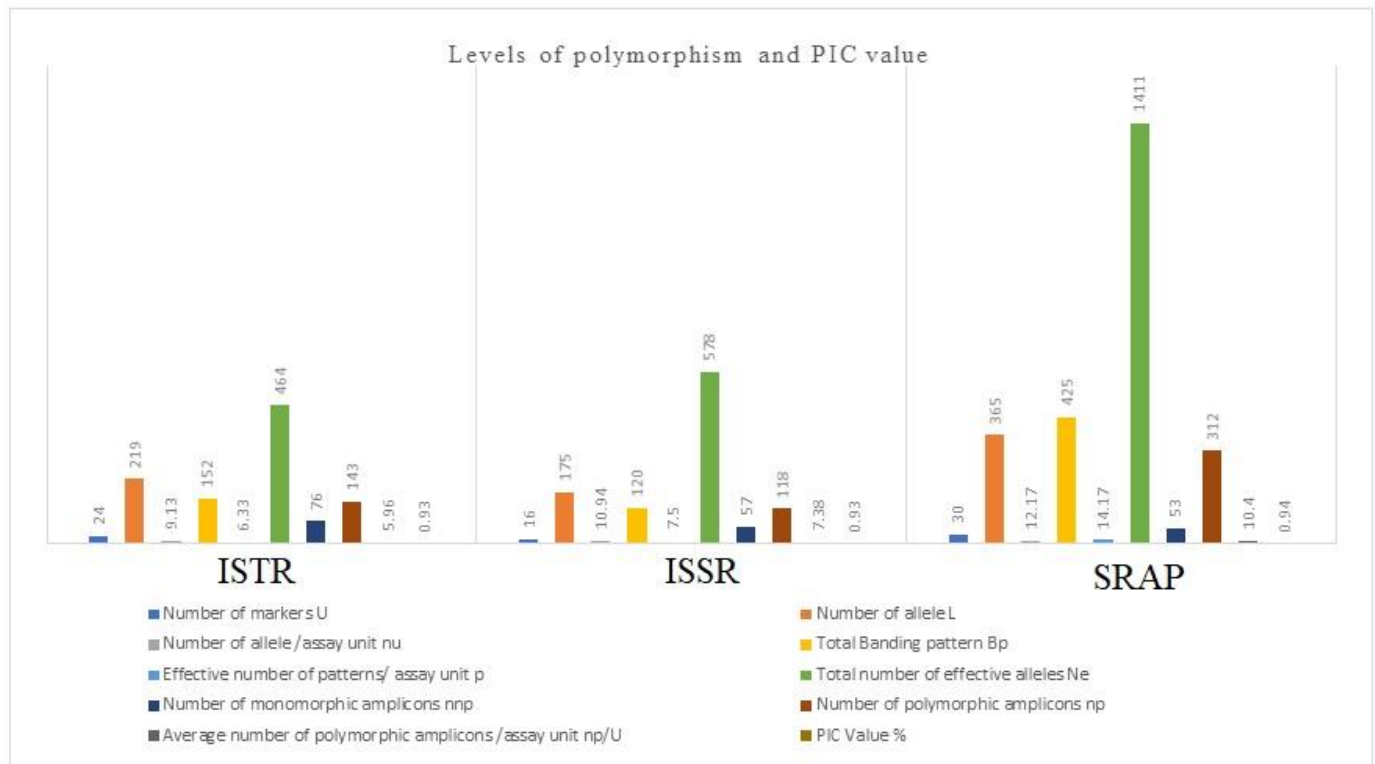

Fig 2. Schematic representation of the Levels of polymorphism and PIC value via SRAP, ISSR and ISTR markers in nine Egyptian varieties of pomegranate. 


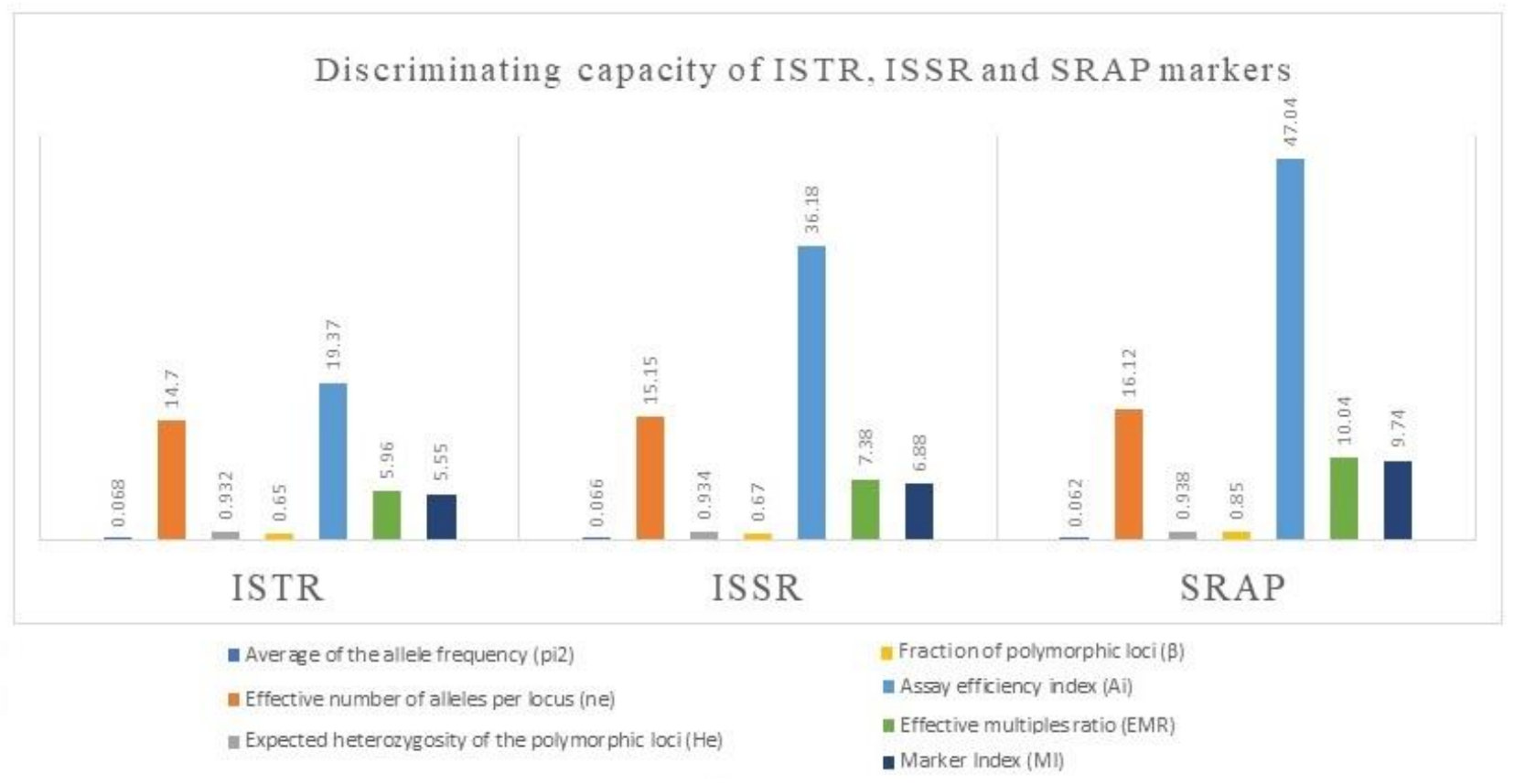

Fig 3. Schematic representation the comparison information obtained and the discriminating capacity of ISTR, ISSR and SRAP markers among nine Egyptian varieties of pomegranate.

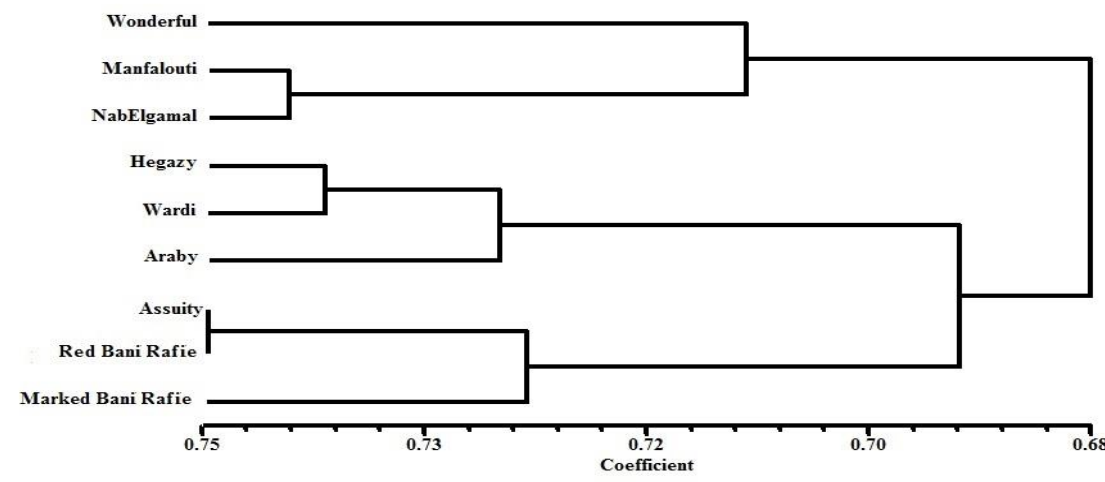

Fig 4. An unweighted pair-group method with arithmetic averages (UPGMA) dendrogram of genetic relationships among nine Egyptian varieties of pomegranate based on the Dice similarity coefficients obtained using the combined data of ISTR, ISSR and SRAP

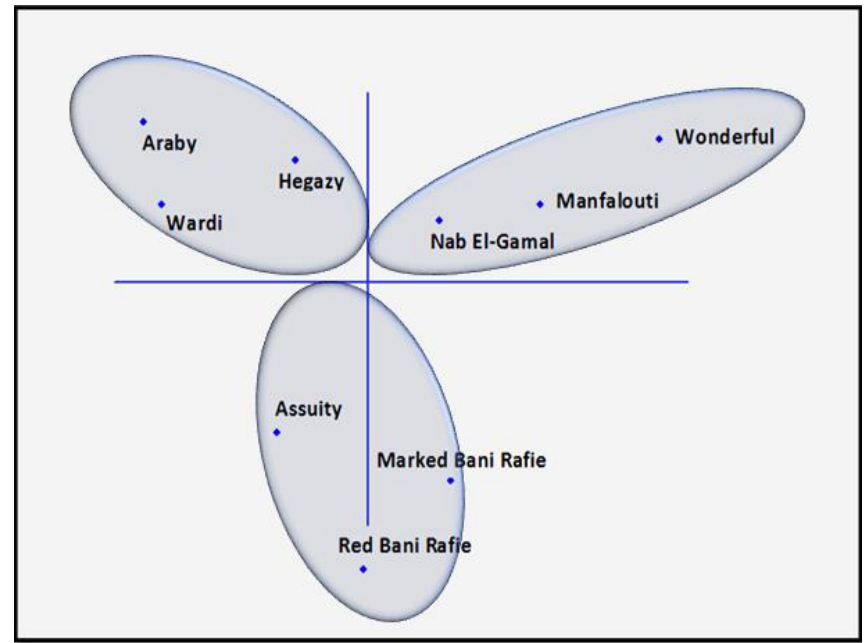

Fig 5. Schematic representation the principal components analysis among nine Egyptian varieties of pomegranate markers. 
2010; Wang et al., 2012; Amar and Abd El Wahab, 2013; Velascoramirez et al., 2014; Costa et al., 2016). In view of the performance of the combined tree and the principal components analysis (PCoA) (Fig 4 and 5), formed groups consistent with the cluster analysis. Our findings demonstrated that both had been reliable sources of information. Hence, our results are clearly distinguishing among the local and the international varieties of performance in Egypt along with three separate categories. Apparently, in view with the previous revisions, our results obtained are better than expected, along with the discrimination capacity and the level of polymorphism when compared to the previous studies in Iran, China, Morocco, Oman and Egypt (Moslemi et al., 2010; Alsadi et al., 2012; Zhao et al., 2013; Ajal et al., 2014; Sinjare, 2015; Al-Sadi et al., 2015; Ismail et al., 2014). In contrast with the previous study in Egyptian pomegranate cultivars created on ISSR and AFLP by Ismail et al., (2014). The low level of polymorphism observed in this study may be due to the little number of cultivars for marker screening and the limited primer selection without the use of filtering steps. Additionally, the analysis of genetic relationship also less resolution in distinctly the differentiate among pomegranate cultivars in Egypt. In the present revised, we can point out that, the two-widespread variety in Egypt Manfalouti and Nab El-Gamal were highly nested genetically with Wonderful variety as a most important global variety for breeding genetics programs. Furthermore, we strongly proposed that Assuity variety is a sister to the pair of varieties Red Bani Rafie, Marked Bani Rafie and could be as a separate closely varieties. This finding is new information and critical for the further breeding program, efforts widening the genetic base of pomegranates and the introduction of new genotypes in Egypt. In this sense, we can point out that our PCA and the combined tree are suitable to confirm the parental relationships with clear resolution within the pomegranate varieties in Egypt along with three separates categories.

\section{Materials and methods}

\section{Plant material}

Pomegranate varieties belong to the gene bank located at the experimental field station of North Sinai Station (NSS), province of North Sinai (Egypt). Nine accessions obtained selected from the varietal groups (Manfalouti; Nab El-Gamal; Hegazy; Wardi; Assuity; Araby) local varieties, and the international varieties (Wonderful; Marked Bani Rafie; Red Bani Rafie). These samples were considered representative to evaluate the method at both the inter- and intra-varietal diversity. Apical sample leaves were randomly collected from adult trees avoiding those reddish one's rich in anthocyanins to not interfere with PCR analysis.

\section{Isolation of genomic DNA (gDNA)}

Total genomic DNA was extracted from a fresh leaf of pomegranate using plant DNA purification mini kit (Thermo Scientific GeneJET kit, K0791, USA) according to manufacturer's protocol. Three to five different DNA preparations were made for each variety. The quality and concentration of the DNA samples were checked in a Quawell Q5000 UV-Vis spectrophotometer (V2.1.4, USA). And a portion of the DNA was diluted to $50 \mathrm{ng} / \mu \mathrm{l}$ for use in ISTR, ISSR and SRAP analysis. Both the stock and diluted portions were stocked at $-20^{\circ} \mathrm{C}$.

\section{ISTR assay}

ISTR assay was carried out according to Aga et al., (2005). ISTR primer combinations were initially screened using a total of 70 primer combinations from ten forward primers and seven reverse primers. Across whole primers screened only 24 ISTR combination (Supplementary Table 1) were chosen for further analysis. Each PCR contained a reaction mixture of $25 \mu \mathrm{l}$ made up of $50 \mathrm{ng}$ of genomic DNA, $200 \mu \mathrm{M}$ of dNTPs, $0.3 \mu \mathrm{M}$ of each primer, $3.5 \mu 1$ of Green PCR buffer, 1 unit of taq DNA polymerase, and deionized water. All reagents and their buffers were supplied by Thermo Scientific Inc, (Germany). PCR amplification was performed in Agilent's (Sure Cycler 8800 thermal cycler, USA), consisted of: 1 cycle at $95{ }^{\circ} \mathrm{C}, 3 \mathrm{~min} ; 40$ cycles of $94{ }^{\circ} \mathrm{C}, 30 \mathrm{~s} ; 45^{\circ} \mathrm{C}, 30$ $\mathrm{s} ; 72{ }^{\circ} \mathrm{C}, 2 \mathrm{~min} ; 1$ cycle at, $72{ }^{\circ} \mathrm{C}, 10 \mathrm{~min} ;{ }^{\circ} \mathrm{C}$ and $4{ }^{\circ} \mathrm{C}$ for infinitive. Agarose gel electrophoresis $(.8 \%)$ used for resolving the PCR amplification products. GeneRuler $100 \mathrm{bp}$ plus DNA ladder (Thermo Scientific, SM0321) was used as the molecular standard to confirm the appropriate ISTR markers. Bands were detected using Bio-Rad Gel Doc ${ }^{\mathrm{TM}}$ $\mathrm{XR}+$ imaging system with Image Lab ${ }^{\mathrm{TM}}$ (USA) (Fig 1a).

\section{ISSR assay}

To execute the ISSR experiment, PCR amplification was performed as described by Sankar and Moore, (2001). Across all ISSR primers screened only sixteen ISSR were selected for further analysis (Supplementary Table 1). ISSR amplifications were performed following the same procedure described for ISTR with minor modifications as follow: 1 cycle at $94{ }^{\circ} \mathrm{C}, 4 \mathrm{~min} ; 35$ cycles of $94{ }^{\circ} \mathrm{C}, 45 \mathrm{~s} ; 45^{\circ} \mathrm{C}, 45 \mathrm{~s}$; $72{ }^{\circ} \mathrm{C}, 1 \mathrm{~min} ; 1$ cycle at, $72{ }^{\circ} \mathrm{C}, 10 \mathrm{~min} ;{ }^{\circ} \mathrm{C}$ and $4{ }^{\circ} \mathrm{C}$ for infinitive (Fig 1b).

\section{SRAP assay}

The SRAP analysis was performed as described by Li and Quiros (2001). SRAP primer combinations (PCs) were screened using 30 different combinations which employed using ten forward, and eleven reverse primers were used (Supplementary Table 1). All reagents and their buffers were supplied by Thermo Scientific Inc, (Germany). Each PCR contained a reaction mixture of $25 \mu \mathrm{l}$ made up of $30 \mathrm{ng}$ of genomic DNA, $200 \mu \mathrm{M}$ of dNTPs, $0.3 \mu \mathrm{M}$ of each primer, $3.5 \mu 1$ of Green PCR buffer, 1 unit of taq DNA polymerase, and deionized water. PCR cycling parameters included $4 \mathrm{~min}$ of denaturing at $94^{\circ} \mathrm{C}$, five cycles of three steps: $1 \mathrm{~min}$ of denaturing at $94^{\circ} \mathrm{C}, 1 \mathrm{~min}$ of annealing at $35^{\circ} \mathrm{C}$ and $1 \mathrm{~min}$ of elongation at $72{ }^{\circ} \mathrm{C}$. In the following 35 cycles, the annealing temperature was raised to $50{ }^{\circ} \mathrm{C}$, and for extension, one cycle of $7 \mathrm{~min}$ at $72{ }^{\circ} \mathrm{C}$. GeneRuler 50 bp Plus DNA Ladder (Thermo Scientific, SM0371) was used as molecular standard to confirm the appropriate SRAP markers (Fig 1c).

\section{Amplicon scoring and data analysis}

Profiles for each variety and marker technique (ISTR, ISSR and SRAP) were constructed by scoring (0) and (1) for absence and presence of bands and assembled onto a data matrix. Comparisons of the discriminating capacity, the level of polymorphism and informativeness of each marker system of ISTR, ISSR and SRAP were calculated according to Belaj et al., (2003), to compare the efficiency of the three markers (ISTR, ISSR and SRAP) in varietals identification, genetic diversity and differentiation. The genetic similarity among the genotypes was estimated according to DICE (qualitative 
data module) coefficients (Dice, 1945; Rohlf, 2000) of the NTSYS-PC software package (version 2.1). The phylogenetic analyses were obtained through clustering analysis by the unweighted pair-group method (UPGMA). To verify the adjustment between similarity matrices and respective dendrogram derived matrices, the cophenetic correlation coefficient $(r)$ was estimated using the software NTSYS PC 2.1 .

\section{Principal components analysis (PCA)}

Principal components analysis (PCA) was carried out to display the multidimensional genetic relationship and its partition among varieties across the binary matrix using TotalLab.TL120.v2009-NULL software (Schlüter and Harris, 2006).

\section{Conclusion}

In the ongoing revised we introduced a highlights utility of ISTR, ISSR and SRAP markers system with a good performance in explaining the genetic diversity, systematic behavior and phylogenetic affinities of the Egyptian pomegranate varieties. As far as we know, here is the first attempt to report a comparison of discriminating capacity, efficiency and the ability of ISTR, ISSR and SRAP in Egyptian pomegranate. Apparently, SRAP assay had more sensitive, higher discrimination capacity and gives much more evidence about the unique genetic background, furthermore to simultaneously detect numerous polymorphic markers per reaction. Our findings confirm that combining different marker system were greatly better and considered an important priority step toward diversity study, characterisation and a prerequisite for more effective breeding programs in pomegranate germplasm.

\section{Acknowledgements}

The authors are thankful to the Dr Mahmoud Magdy Elmosallamy, Assistant Professor, Department of Genetics, Faculty of Agriculture, Ain Shams University, for the analysis of data and his support and offers in this revised. The partial financial support from the Genebank Research program, Desert Research Center, (DRC), Egypt, is gratefully acknowledged.

\section{Author's contribution}

Mohamed Abd. S. El Zayat carried out the experiments. Amar planned the project and performed the analysis of data and writing of the manuscript.

\section{Conflict of interest}

The authors declare that they have no conflict of interest.

\section{Reference}

Aga E, Bryngelsson T (2005) Inverse Sequence-tagged Repeat (ISTR) Analysis of Genetic Variability in Forest Coffee (Coffea arabica L.) from Ethiopia. Genet Resour Crop Ev. 53:721-728.

Agarwal M, Shrivastava N, Padh H (2008) Advances in molecular marker techniques and their applications in plant sciences. Plant Cell Rep. 27: 617-631.

Ajal EA, Jbir R, Melgarejo P, Hernandez F, Haddioui A, Hannachi AS (2014) Efficiency of Inter Simple Sequence
Repeat (ISSR) markers for the assessment of genetic diversity of Moroccan pomegranate (Punica granatum L.) cultivars. Biochem Syst Ecol. 24-31.

Alsadi AM, Alfahdi AR, Alyahyai R, Alghaithi AG, Alsaid F A, Soleiman MJ (2015) Genetic analysis suggests a shared origin of Punica granatum cultivars in Oman with cultivars from the center of origin, Iran. Genet Resour Crop Ev. 62: 815-821.

Alsadi AM, Almoqbali HS, Alyahyai R, Alsaid FA (2012) AFLP data suggest a potential role for the low genetic diversity of acid lime (Citrus aurantifolia Swingle) in Oman in the outbreak of witches' broom disease of lime. Euphytica.188: 285-297.

Amar MH, Abd El Salam M (2013) Retro transposonmarkers: an overview of the recent progress in Citrus germplasm. J Bio Env Sci. 3: 31-41.

Amar MH, Abd El Wahab M (2013) Comparative genetic study among Origanum L. plants grown in Egypt. J Bio Env Sci. 3:208-222.

Amar MH, Biswas MK, Zhang Z, Guo W (2011) Exploitation of SSR, SRAP and CAPS-SNP markers for genetic diversity of Citrus germplasm collection. Sci Hortic. 128: 220-227.

Aneja B, Yadav NR, Chawla V, Yadav RC (2012) Sequencerelated amplified polymorphism (SRAP) molecular marker system and its applications in crop improvement. Mol Breed. 30: 1635-1648.

Belaj A, Satovic Z, Cipriani G, Baldoni L, Testolin R, Rallo L, Trujillo I (2003) Comparative study of the discriminating capacity of RAPD, AFLP and SSR markers and of their effectiveness in establishing genetic relationships in olive. Theor Appl Genet. 107: 736-744.

Biswas MK, Chai L, Amar MH, Zhang X, Deng X (2011) Comparative analysis of genetic diversity in Citrus germplasm collection using AFLP, SSAP, SAMPL and SSR markers. Sci Hortic. 129: 798-803.

Chandra R, Babu DK, Jadhav VT, Teixeira da Silva, JA, (2010) Origin, history and domestication of pomegranate. In: Chandra, R. (Ed.), Pomegranate. Fruit Veg Cereal Sci Biotechnol. 4: Special Issue 2: 1-6.

Chauhan RD, Kanwar K (2012) Biotechnological advances in pomegranate (Punica granatum L.). In Vitro Cellular Developmental Biology - Plant. 48: 579-594.

Costa R, Pereira G, Garrido I, Tavaresdesousa M, Espinosa F (2016) Comparison of RAPD, ISSR, and AFLP molecular markers to reveal and classify Orchard grass (Dactylis glomerata L.) germplasm variations. Plos One. 11: 4.

Dice LR (1945) Measures of the amount of ecologic association between species. ecology 26:297-302.

Dong P, Wei Y, Chen G, Li W, Wang J, Nevo E, Zheng Y (2010) Sequence-related amplified polymorphism (SRAP) of wild emmer wheat (Triticum dicoccoides) in Israel and its ecological association. Bio Syst Eco. 38:1-11.

Du X, Zhang Q, Luo Z (2009) Comparison of four molecular markers for genetic analysis in Diospyros L. (Ebenaceae). Plant Syst Evol. 171-181.

Ferrao LF, Caixeta ET, Souza FD, Zambolim EM, Cruz CD, Zambolim L, Sakiyama NS (2012) Comparative study of different molecular markers for classifying and establishing genetic relationships in Coffea canephora. Plant Syst Evol. 299: 225-238.

Ghobadi S, Khosh-Khui M, Tabatabae BES (2005) Phylogenetic relationships among some Iranian pomegranate accessions revealed by inter-simple sequence repeat (ISSR) markers. Iranian J Hort Sci Techn. 6:111120. 
Hajiahmadi Z, Talebi M, Sayedtabatabaei BE (2013) Studying Genetic Variability of Pomegranate (Punica granatum L.) Based on Chloroplast DNA and Barcode Genes. Mol Biotechnol. 55: 249-259.

Hasnaoui N, Buonamici A, Sebastiani F, Mars M, Zhang D, Vendramin GG (2012) Molecular genetic diversity of Punica granatum L. (pomegranate) as revealed by microsatellite DNA markers (SSR). Gene. 493: 105-112.

IPGRI (2001) Regional Report CWANA 1999-2000, International Plant Genetic Resources Institute, Rome, Italy.145-178.

Ismail OM, Younis RA, Ibrahim AM (2014) Morphological and molecular evaluation of some Egyptian pomegranate cultivars. Afr J of Biotec. 13:226-237.

Jhang T, Kaur M, Kalia P, Sharma TR (2010) Efficiency of different marker systems for molecular characterization of subtropical carrot germplasm. J Agric Sci. 148:171-81. 1.

Kalendar R (2011) The use of retro transposonbased molecular markers to analyze genetic diversity. Field Vegetable Crop Res. 48: 261-274.

Koohi-Dehkordi M, Sayed-Tabatabaei BE, Yamchi A, Daneshshahraki A (2007) Microsatellites markers in pomegranate. Acta Hort. 760:179-183.

Kumar R, Yadav SS, Mishra SK, Srivastav AK, Tripathi M (2013) Molecular markers of aromatic and medicinal plants. Inter J Pharma Sci. 4: 344- 362.

Levin G M (2006a) Pomegranate Roads: A Soviet Botanist's Exile from Eden, 1st Edn. Floreant Press, Forestville, California. 15-183.

Levin G M (2006b) Pomegranate, 1st Edn. Third Millennium Publishing, East Libra Drive Tempe, AZ. 1-129.

Li G, McVetty PB, Quiros CF (2013) SRAP molecular marker technology in plant science. In: Andersen SB (ed) Plant breeding from laboratories to fields. 23-43. doi: $10.5772 / 54511$.

Li G, Quiros CF (2001) Sequence-related amplified polymorphism (SRAP), a new marker system based on a simple PCR reaction: its application to mapping and gene tagging in Brassica. Theor Appl Genet. 455-461.

Li H, Ruan CJ, Silva T, Jaime A, Liu BQ (2010) Associations of SRAP markers with dried-shrink disease resistance in a germplasm collection of sea buckthorn (Hippophae rhamnoides L.). Genome. 53: 447-457.

Liu L, Zhu X, Gong Y, Song X, Wang Y, Zhao L, Wang L (2007) Genetic diversity analysis of radish germplasm with RAPD, AFLP and SRAP markers. Acta Hort. 760:125130.

Li-Wang L, Li-Ping Z, Yi-Qin G, Ming-Xia W, Li-Ming C, Jin-Lan Y, Yan W, Fan-Min Y, Long-Zh W (2008) DNA fingerprinting and genetic diversity analysis of late-bolting radish cultivars with RAPD, ISSR and SRAP markers. Sci Hortic. 116:240-247.

Melgarejo, P, Martinez J J, Hernandez F, Martinez R, Legua P, Oncina R, Martinezmurcia A (2009) Cultivar identification using 18S-28S rDNA intergenic spacerRFLP in pomegranate (Punica granatum L.). Sci Hortic. 120: 500-503.

Milbourne D, Meyer R, Bradshaw JE, Baird E, Bonar N, Provan J, Powell W, Waugh R (1997) Comparison of PCRbased marker systems for the analysis of genetic relationships in cultivated potato. Molecular Breed. 3:127136.

Moslemi M, Zahravi M, Khaniki GB (2010) Genetic diversity and population genetic structure of pomegranate (Punica granatum L.) in Iran using AFLP markers. Sci Hortic. 126; 441-447.
Narzary D, Mahar KS, Rana TS, Ranade SA (2009) Analysis of genetic diversity among wild pomegranates in Western Himalayas, using PCR methods. Sci Hortic.121: 237-242.

Narzary D, Rana T S, Ranade SA (2010) Genetic diversity in inter-simple sequence repeat profiles across natural populations of Indian pomegranate (Punica granatum L.). Plant Biology. 12: 806-813.

Pirseyedi S M, Valizadehghan S, Mardi M, Ghaffari MR, Mahmoodi P, Zahravi M, Nekoui SM (2010) Isolation and characterization of novel microsatellite markers in pomegranate (Punica granatum L.). Inter J Mol Sci. 1: 2010-2016.

Pitsiouni M, Linos A, Hagidimitriou M (2012) Genetic diversity of greek wild and cultivated pomegranate (Punica granatum L.) genotypes and cultivars using molecular markers. Acta Hort. 940. 193-200.

Rana JC, Pradheep K, Verma VD (2007) Naturally occurring wild relatives of temperate fruits in western Himalayan region of India: an analysis. Bio Cons. 16: 3963-3991.

Ranade S A, Rana T S, Narzary D (2009) SPAR profiles and genetic diversity amongst pomegranate (Punica granatum L.) genotypes. Phy Mol Biology Plants. 15: 61-70.

Rania J, Salwa Z, Najib H, Amal BD, Messaoud M, Amel, S $\mathrm{H}$ (2012) Microsatellite polymorphism in Tunisian pomegranates (Punica granatum L.): Cultivar genotyping and identification. Bio Syst Eco. 27-35.

Rhode W (1996) Inverse sequence-tagged repeat (ISTR) analysis. A novel and universal PCR (polymerase chain reaction)-based technique for genome analysis in plant and animal kingdom. J Genet Breed.50:249-61.

Robarts DWH, Wolfe AD (2014) Sequence-related amplified polymorphism (SRAP) markers: a potential resource for studies in plant molecular biology. Plant Sci. 2: doi:10.3732/apps.1400017.

Rohlf FJ (2000) NTSYS-pc: numerical taxonomy and multivariate analysis system, version 2.1. Exeter Software, New York.

Sankar AA, Moore GA (2001) Evolution of inter simple sequence repeat analysis from mapping in Citrus and extension of the genetic linkage map. Theor Appl Genet. 102: 206-214

Sarkhosh A, Zamani Z, Fatahi R, Ebadi A (2006) RAPD markers reveal polymorphism among some Iranian pomegranate (Punica granatum L.) genotypes. Sci Hortic. 111: $24-29$

Scariot V, De Keyser E, Handa T, De Riek J (2007) Comparative study of the discriminating capacity and effectiveness of AFLP, STMS and EST markers in assessing genetic relationships among evergreen azaleas. Plant Breeding. 126: 207-212.

Schlüter PM, Harris SA (2006) Analysis of multilocus fingerprinting data sets containing missing data. Mol Ecol Notes. 6: 569-572.

Silva JA, Rana TS, Narzary D, Verma N, Meshram DT, Ranade SA (2013) Pomegranate biology and biotechnology: A review. Sci Hortic. 85-107.

Sinjare DY (2015) Application of microsatellite SSR markers in a number of pomegranate (Punica granatum L.) cultivars in Kurdistan region/Duhok orovince. Int J Chem Biomol Sci. 1:117-122.

Soleimani M, Talebi M, Sayedtabatabaei BE (2012) Use of SRAP markers to assess genetic diversity and population structure of wild, cultivated, and ornamental pomegranates (Punica granatum L.) in different regions of Iran. Plant Syst Evol. 298: 1141-1149. 
Talebi Bedaf M, Sharifnabi B, Bahar M (2003) Analysis of genetic diversity in pomegranate cultivars of Iran, using random amplified polymorphic DNA (RAPD) markers. In: Proceedings of the 3rd National Congress of Biotechnology. Iran. 2:343-345.

Talebi M, Bahar M, Sharifnabi B, Yamchi A (2011) Evaluation of genetic diversity among Iranian pomegranate (Punica granatum L.) cultivars, using ISSR and RAPD markers. Taxon Biosyst. 8:35-44.

Talebi M, Ghobadi C, Yamchi A, Sayed Tabatabaei BE, Bahar M (2005) Using of ISSR markers to investigate the genetic diversity in some Iranian pomegranate. In: Proceedings of 8th Congress on Agricultural Plant Breeding Iran. 34.

Torresmoran MI, Almarazabarca N, Escotodelgadillo M (2012) ISTR, a retrotransposons-based marker to assess plant genome variability with special emphasis in the genera Zea and Agave. American JPlant Sci. 3: 1820-1826.
Velascoramirez AP, Torresmoran MI, Molinamoret S, Sanchezgonzalez JD, Santacruzruvalcaba F (2014) Efficiency of RAPD, ISSR, AFLP and ISTR markers for the detection of polymorphisms and genetic relationships in camote de cerro (Dioscorea spp.). Elec J Biot.17: 65-71.

Wang Z, Wang J, Wang X, Gao H, Dzyubenko NI, Chapurin VF (2012) Assessment of genetic diversity in Galega officinalis L. using ISSR and SRAP markers. Genet Resour Crop Ev.59: 865-873.

Yuan Z, Yin Y, Qu J F, Zhu L, Li Y (2007) Population genetic diversity in Chinese pomegranate (Punica granatum L.) cultivars revealed by fluorescent-AFLP markers. J Genet Genom. 34: 1061-1071.

Zhao L, Li M, Cai G, Pan T, Shan C (2013) Assessment of the genetic diversity and genetic relationships of pomegranate (Punica granatum L.) in China using RAMP markers. Sci Hortic. 63-67. 